\title{
Fluorescent sentinel lymph node mapping with icg in endometrial cancer. An initial experience in Argentina
}

\begin{abstract}
Background: Near-infrared fluorescence-based sentinel lymph node (SLN) mapping technique with indocyanine green (ICG) has been found a useful surgical modality for sentinel node detection and disease staging in endometrial cancer (EC) worldwide.

Objective: We aimed to introduce the SNL mapping technology using ICG and Near Infrared (NIR) fluorescence in Argentina. We aimed to assess the overall and bilateral detection rate of ICG based SNL mapping along with verifying its feasibility and effectiveness in surgical staging. We also aimed to discover the perceptions of surgeons regarding the use of ICG as a tracer and NIR as light-medium in SNL mapping.

Method: ICG SLNs identification was evaluated retrospectively. This study was performed at the Hospital Aleman de Buenos Aires in September, 2017The detection rates were calculated along with the analysis of the number of SNL observed and operative time, and time taken by overall surgery. Subsequently, the surgeons were interviewed to ascertain their opinion of using ICG SNL mapping in endometrial cancer staging.

Results: Four patients with endometrial cancer were included for analysis. The overall and bilateral detection rates have been $100 \%$ and $75 \%$, respectively. While, under white light, no SLNs were identified. The average operative time of nodes resection was estimated 2.15 minutes. The fluorescence has been used for 2.2 minutes and overall time taken by surgery was estimated 71.5 minutes. The estimated blood loss (EBL) has been lower than $50 \mathrm{ml}$. The responses of surgeons' from the interview have been $100 \%$ positive. The cost of the procedure based on the amount of dye used was 25 dollars per patient.
\end{abstract}

Conclusion: Laparoscopic ICG SLN resulted to be feasible, practical and no expensive surgical modality for uterine cancer triage.

\section{Background}

Endometrial cancer (EC) is one of the most prevalent and increasing gynecological malignancy worldwide, especially in developed countries. Screening of lymph node metastases serves as a significant contributor to timely prognosis and delivers substantial oncologic information. ${ }^{1}$ The surgical approach for detecting the cancer stage in uterine cancers has been controversial, and it is suggested that conducting the pelvic or para-aortic lymphadenectomy for screening early-stage metastases can deliver adverse and unpropitious outcomes. Various approaches were introduced and evaluated for the same purpose that can impose minimal risk in any stage of EC. ${ }^{2-4}$

The intra-operative procedures in uterine cancer patients have been found very risky, but due to scarce knowledge and data, there was no other option except extensive lymphadenectomy which has been found to be associated with high morbidity. In recent years, the advancement of medical technology has led to the development of fluorescent sentinel lymph node (SLN) mapping in various tumor development sites. ${ }^{5}$ Earlier it has been successfully implemented in the screening of other tumors including malignant melanoma, breast cancer, ${ }^{6}$ bladder cancer ${ }^{7}$ and vulvar cancer. Due to its effectiveness and successful application, the fluorescent SLN approaches were proposed to be adopted for uterine cancer triage, especially EC and cervical cancer. ${ }^{8}$

The primary aim of this analysis was to evaluate the effectiveness of fluorescent technique of SLN mapping in EC staging using ICG dye in Argentina.
Volume 12 Issue 6 - 202I

\author{
Federico Bianchi MD,' Alfredo Camargo MD \\ PhD,' Fernando Dip MD, ${ }^{2,3}$ Diego Habich \\ MD,' Tomas Ramilo MD,' Tomas Garcia \\ Balcarce MD,' Codoni Maria Jose MD,' \\ Roberto Castaño MD PhD,' Raul Rosenthal \\ MD, FACS, FASMBS, ${ }^{2}$ Di Sanzo Natalia ${ }^{3}$ \\ 'Hospital Aleman, Buenos Aires, Argentina \\ ${ }^{2}$ Cleveland Clinic, Weston Florida, USA \\ ${ }^{3}$ Surgery assistant, Hospital Aleman, Buenos Aires, Argentina
}

Correspondence: Alfredo Camargo, Gynecology Service, German hospital. Buenos Aires (CABA), Universidad de Buenos Aires, Argentina, Tel 549I I54046953,

Email alfrecamargo@yahoo.com

Received: December 07, 202I | Published: December 17, 2021

\section{Materials and methods}

This study is conducted at Hospital Aleman de Buenos Aires in September 2017. Firstly, the four cancer patients were randomly selected between the age range of 55-87, for retrieving the clinicopathological data and oncologic information using proposed techniques. Physicians were interviewed, and their responses were collected to analyze the comfort of using the device.

A Storz SPIES Full HD D-Light P ICG technology (Karl Storz, Mittelstrasse, Tuttlingen, Germany) was used. Indocyanine green (Verdy) was used as a tracer, and NIR light was used to screen the SLNs.

To evaluate the applicability and effectiveness of ICG with NIR fluorescence based SLN mapping in oncology surgeries, different previous studies were analyzed. ${ }^{2,-11}$

The solution with ICG was prepared with $25 \mathrm{mg}$ of ICG powder diluted into $10 \mathrm{ml}$ of sterile aqueous water. Afterwards $2 \mathrm{ml}$ of this solution was injected into cervix in two distinct positions, 3- and 9o'clock positions. Half milliliter of ICG solution was administered with penetration to $1 \mathrm{~cm}$ deep into the stroma, and $0.5 \mathrm{~mL}$ was administered into the submucosal layer on both sides of the cervix. Subsequently, the NIR fluorescence was applied for SLN mapping, and the findings were recorded and analized (Table 1) (Table 2). The main variables that were determined for assessing the efficiency level of this technique in this series of research included time of migration of the dye, number of SLN detected with fluorescence in the pelvis, 
and the number of lymph vessels visualized. Moreover, we sought to evaluate the surgeons satisfaction, operative time and the time the fluorescent system was used.
After that, the four surgeons involved in this study were interviewed based on seven-questions regarding their experiences and findings of the technique (Table 3).

Table I Data gathered from the initial experiment of SNL mapping using ICG under NIR light in comparison of white light

\begin{tabular}{|c|c|c|c|c|c|c|c|c|c|c|c|c|c|}
\hline Age & Pathology & $\begin{array}{l}\text { SLNs } \\
\text { found } \\
\text { with } \\
\text { white } \\
\text { light } \\
\text { right } \\
\text { side }\end{array}$ & $\begin{array}{l}\text { SLNs } \\
\text { under } \\
\text { NIR } \\
\text { light } \\
\text { left } \\
\text { side }\end{array}$ & $\begin{array}{l}\text { SLNs } \\
\text { under } \\
\text { NIR } \\
\text { light } \\
\text { right } \\
\text { side }\end{array}$ & $\begin{array}{l}\text { ICG } \\
\text { dose }\end{array}$ & $\begin{array}{l}\text { Site of } \\
\text { injec-tion }\end{array}$ & $\begin{array}{l}\text { Time of } \\
\text { initialmigra- } \\
\text { tion }\end{array}$ & $\begin{array}{l}\text { Time } \\
\text { to } \\
\text { identify } \\
\text { SLN } \\
\text { with } \\
\text { ICG }\end{array}$ & $\begin{array}{l}\text { Vessels } \\
\text { visual- } \\
\text { ized }\end{array}$ & $\begin{array}{l}\text { Surgeon } \\
\text { Satisfac- } \\
\text { tion } \\
\text { Rate (1 } \\
-10)\end{array}$ & $\begin{array}{l}\text { Opera- } \\
\text { tive Time } \\
\text { (resect- } \\
\text { ion of } \\
\text { nodes } \\
\text { once the } \\
\text { node was } \\
\text { detected) }\end{array}$ & $\begin{array}{l}\text { Total } \\
\text { Time } \\
\text { of the } \\
\text { use of } \\
\text { fluore- } \\
\text { scence }\end{array}$ & $\begin{array}{l}\text { Overall } \\
\text { time } \\
\text { taken } \\
\text { by } \\
\text { surgery }\end{array}$ \\
\hline 66 & $\begin{array}{l}\text { Endometrial } \\
\text { Adenocarcinoma }\end{array}$ & 0 & 0 & 2 & $5 \mathrm{mg}$ & $\begin{array}{l}\text { 3у9 } 0 \\
\text { clockcervix }\end{array}$ & $3 \mathrm{~min}$ & $6 \mathrm{~min}$ & 3 & 8 & $1.3 \mathrm{~min}$ & 2.5. $\min$ & $55 \mathrm{~min}$ \\
\hline 87 & $\begin{array}{l}\text { Endometrial } \\
\text { Adenocarcinoma }\end{array}$ & 0 & 2 & 1 & $50 \mathrm{mg}$ & $\begin{array}{l}3 \text { у9 } 0 \\
\text { clock } \\
\text { cervix }\end{array}$ & $4 \mathrm{~min}$ & $6,30 \mathrm{~min}$ & 4 & 10 & $3.1 \mathrm{~min}$ & $2.7 \mathrm{~min}$ & $70 \mathrm{~min}$ \\
\hline 55 & $\begin{array}{l}\text { Endometrial } \\
\text { Adenocarcinoma }\end{array}$ & 0 & 1 & 1 & $5 \mathrm{mg}$ & $\begin{array}{l}\text { 3у9 } 0 \\
\text { clockcervix }\end{array}$ & $5 \mathrm{~min}$ & $7,30 \mathrm{~min}$ & 2 & 10 & $2.2 \mathrm{~min}$ & $1.9 \mathrm{~min}$ & $68 \mathrm{~min}$ \\
\hline 65 & $\begin{array}{l}\text { Endometrial } \\
\text { Adenocarcinoma }\end{array}$ & 0 & 1 & 1 & $5 \mathrm{mg}$ & $\begin{array}{l}\text { O } \\
\text { clock3y9 } \\
\text { cervix }\end{array}$ & $5 \mathrm{~min}$ & $6,50 \mathrm{~min}$ & 4 & Not sure & 10 & $2.0 \mathrm{~min}$ & $93 \mathrm{~min}$ \\
\hline
\end{tabular}

Table 2 Clinicopathologic characteristics of patients

\begin{tabular}{ll}
\hline Patients (N) & $\mathbf{4}$ \\
\hline Median age, years (range) & $65.5(55-87)$ \\
Mean age & 68.25 \\
Patients with lymph node metastasis & $0 \%(0 / 4)$ \\
Numbers of SLN detected on right side & $100 \%$ \\
Numbers of SLN detected on left side & $75 \%(3 / 4)$ \\
\hline
\end{tabular}

Table 3 Data gathered from interviewing four surgeons'

\begin{tabular}{|c|c|c|c|c|}
\hline Surgeons' opinion & Surgeon I & Surgeon 2 & Surgeon 3 & Surgeon 4 \\
\hline Do you find the method useful? & Yes & Yes & Yes & Yes \\
\hline Did you find it practical $(I-I 0)$ ? & 10 & 10 & 10 & 10 \\
\hline How frequently would you use it? (never, sometimes or always) & Always & Always & Always & Always \\
\hline Did the method guide you to the procedure? & Yes & Yes & Yes & Yes \\
\hline Did you find the method safe? & Yes & Yes & Yes & Yes \\
\hline
\end{tabular}

\section{Results}

The findings from the applied technique showed the comparative results from the mapping (Figures 1-5).

The median age of the participants were 65.5 (55-87). When white light was used no SLNs were identified. When NIR light was used, SLNs were identified in all the patients (4/4), 100\% and in 3 out of 4 patients bilateral nodes were detected $75 \%$ (Figure 6).

The mean time of migration of ICG has been estimated as 4.25 minutes, and identification process of SLNs took an average of 6.52 minutes. Overall 13 lymph vessels were visualized in 4 patients. No metastasis was observed in detected SLNs. Mean surgeon satisfaction rate was 9.5 (95\%). The mean operative time of nodes resection was estimated in 2.15 minutes.. The mean time of the use of fluorescence was 2.2 minutes. The overall surgical time was 71.5 minutes. The EBL (estimated blood loss) was less than $50 \mathrm{ml}$ for each case. The cost of fluorescent SLN identification was 25 dollars per patient.

The interview responses delivered $100 \%$ positive responses from the surgeons (Table 3). The significant advantages of ICG based SLN mapping has been found fast, cost-effective and inexpensive. 
All the patients were discharged two days after the procedure without any complications.

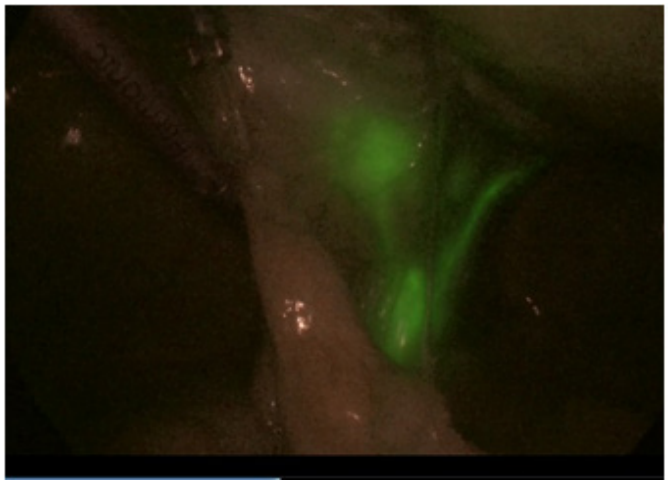

Figure I Pelvic Lymphatic flow.

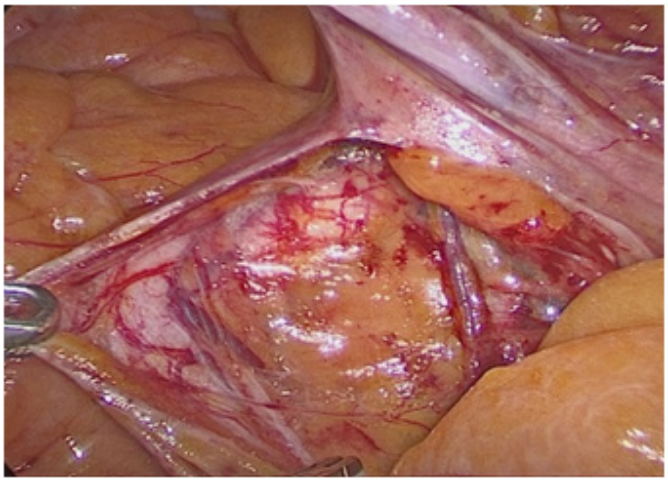

Figure 2 Pelvic dissection.

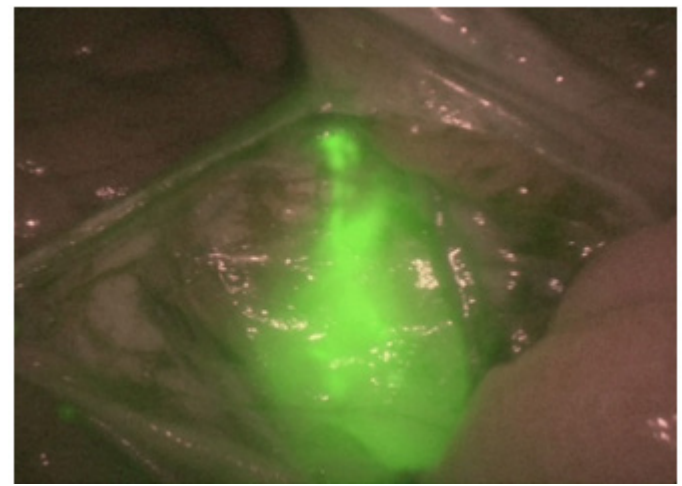

Figure 3 SIN identification.

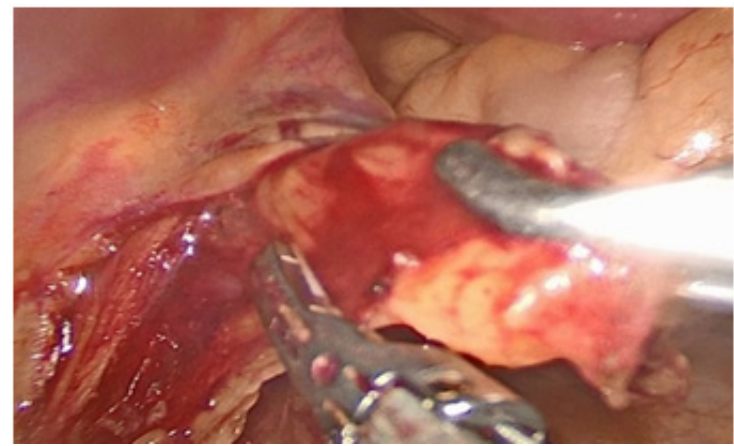

Figure 4 SLN resection With White light.

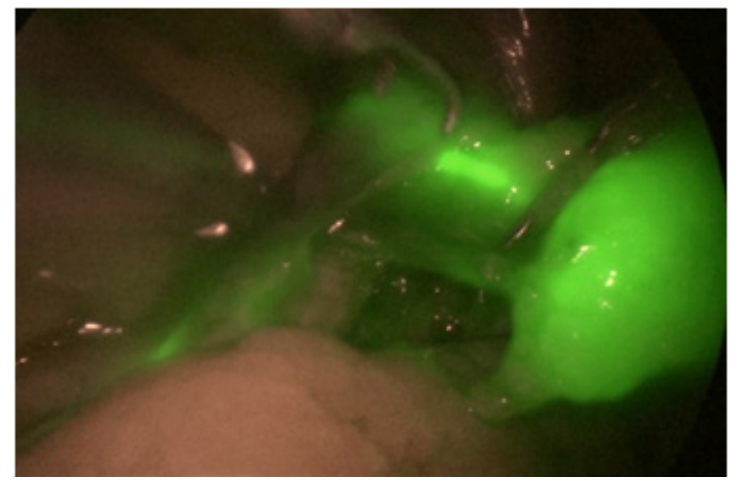

Figure 5 SLN resection With Near Infrared light.

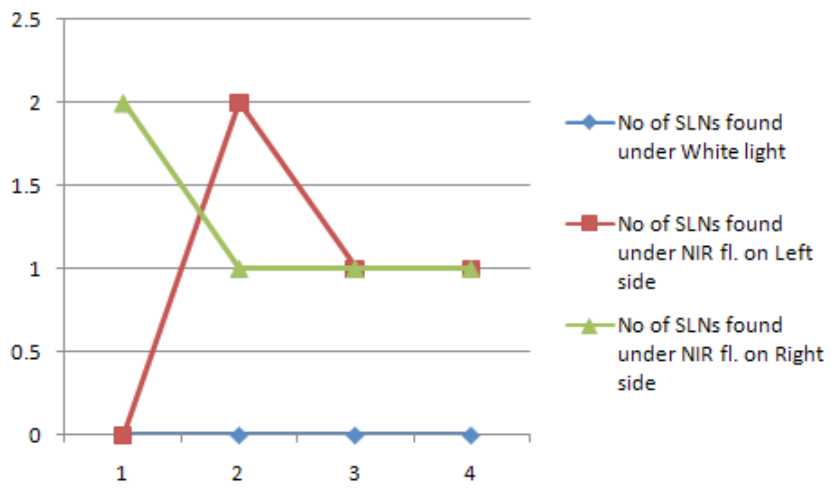

Figure 6 Chart showing a comparative graph for SLN detect under White light and NIR in left and right side ( $x$ axis-Patients \& y axis-no. of SLNs).

\section{Discussion}

The present retrospective pilot study included four patients and delivered $100 \%$ and $75 \%$ overall and bilateral detection rates that are parallel to the results of Plante and Papadia's work. ${ }^{2,4,12,13}$ The major points that are concluded by this research are that ICG serves an excellent and safe tracer for NIR fluorescence-based SLN mapping. It also delivers the highest overall and bilateral detection rate in comparison to other options, including blue dye, $99 \mathrm{mTC}$ (technetium$99 \mathrm{~m}$ radiocolloid) and the use of white light. ${ }^{10}$ Previous studies have shown the potential of ICG as a tracer in NIR fluorescence in SLN mapping which is confirmed by the results of this retrospective study. Multiple studies have established the outstanding performance of ICG in SLN detection. ${ }^{2,3,9,10,11,14}$ The little variations are seen among the results from these studies which may be due to the various sample size chosen for the studies.

In this process, the cervical injection was filled with indocyaninegreen (ICG) fluorescent dye followed by near-infrared fluorescence (NIR) imaging. It has delivered abundant outcomes in all type of surgeries including laparoscopic, open as well as robot-assisted surgery. It has been reported that ICG induced fluorescence in SLN mapping has been more productive and achieves higher total and bilateral pelvic SLNs detection-rates with reduced false negative rates and no side-effects. ${ }^{15,16}$

A UK based prospective study confirmed that SLN mapping might diminish surgical morbidity risk associated with lymphadenectomy. It discovered that SLN using ICG induced NIR fluorescence in open as well as laparoscopic surgeries delivered $100 \%$ optimization and detection rate for all type of cancers including uterine and vulvar. ${ }^{17}$ 
Buda and co-researchers ${ }^{9}$ conducted a comparative study with the aim of determining the detection rate and optimal bilateral mapping of SLNs using ICG, standard $99 \mathrm{mTc}$ and blue dye. This study concluded that SLN mapping using ICG delivers higher detection rate in comparison to other dyes. Furthermore, it has been shown superior performance in optimal bilateral mapping for early-stage cancer. The early prophylaxis through ICG based SLN mapping offers twofold advantages, firstly, it decreases the requirement of complete lymphadenectomies and secondly, it cuts the cost of the extensive surgical procedure and additional surgical expenses. ${ }^{9,18}$ This fact was further strengthened by the evidence provided by How et al. ${ }^{11}$ The authors highlighted the expediency and superior sensitivity of ICG dye in SLN mapping for para-aortic and pelvic areas. ${ }^{11}$ Papadia et al. showed a lower rate of false negative (FN) rate $(8.3 \%)$ with almost $96 \%$ overall detection rate and $88 \%$ bilateral detection rates. ${ }^{2}$

The SLN mapping facilitates sensitive detection of lymph node metastases with the less comprehensive process and surgical trauma. The other significant advantage of SLN mapping approach is that it provides an effective staging procedure facilitating an appropriate triage of the patient for adjuvant therapies. SLN mapping technique is also associated with lower estimated blood loss and less operative time. ${ }^{2}$ It is suggested that SLN mapping approach has filled a significant gap between the extensive lymphadenectomy and no lymphadenectomy options in EC staging. ${ }^{3,19}$

The NIR fluorescent activation provides normal-colored anatomy expressions. ${ }^{4}$ The comparative analysis of imaging techniques for SLN mapping also confirmed that ICG as a tracer is the best modality superior to other options of colorimetric imaging ${ }^{20}$ or imaging under white light. ${ }^{10}$

We believe that the attained overall and bilateral detection rates in this study were contributed by the chosen tracer, ICG. Furthermore, in ICG based SLN mapping the risk of negative impact of BMI on detection is also diminished which is mainly faced with the other dyes like ISB (isosulfan blue). ${ }^{21,22}$ This finding was supported by Holloway et al. ${ }^{10}$ through a cohort study in which they showed the additional probability of improvement in detection accuracy from NIR technique. In this study, the authors emphasized that the detection rate of NIR fluorescence was further enhanced by adding ICG with ISB dye. The increased accuracy was evaluated in this case for detecting high numbers of SLNs and LN metastases in comparison of ISB alone. This combination produced higher detection rate and sensitivity without any risk of adverse outcome. ${ }^{10}$

In this retrospective pilot study, a small group of surgeons was interviewed, and their responses were gathered. Their experience and perceptions regarding the applicability of ICG in SLN mapping were assessed and compared for determining the values of defined variables. Their responses were similar to the predicted results from the other studies. The involved surgeons provided 100\% feedback about its feasibility, detection rate and diagnostic accuracy in cancer patients. According to the literature most surgeons prefer to use dyes in SLN mapping in comparison of radioactive colloid due to the high potency, technical ease and cost-effectiveness. ${ }^{10}$ The surgeons found SLN mapping feasible and oncologically safe. The comparative evaluation of features, toxicity and clinical implications of $99 \mathrm{mTC}$ radiocolloid, blue dyes (including methylene blue, and isosulfan blue) and ICG revealed that ICG possesses an outstanding toxicity profile with higher overall as well as bilateral detection rates than blue dyes. ${ }^{23}$ Moreover, it has been shown superior detection rate with the NIR technology when compared to $99 \mathrm{mTC}$ and blue dye. ICG use as a tracer during mapping negates the impact of BMI on detection rates. Overall, SLN with ICG offers a cost-effective approach which is favored by surgeons as well as patients too. ${ }^{24,25}$

The weakness of this study is the small number of patients. Though, it has met all of its objectives and delivered the outcomes as expected.

The interview-based experiment also showed that the surgeons prefer this technique due to its nil toxicity, high detection rate and less extensive surgical procedure as well as less surgical trauma on patients. It has offered the best modality for SLN mapping in uterine malignancies. Its ease, no radiation exposure, cost-effectiveness, and quick procedures have led the surgeons to prefer it over other options.

\section{Conclusion}

This research showed that laparoscopic fluorescent SLN mapping using ICG is a feasible and cost effective surgical modality in oncologic staging, especially for endometrial cancer. SNL mapping in endometrial cancer with ICG plus NIR fluorescence is a valid option for staging purpose and it fills the gap between the choice of the complete lymphadenectomy or nothing, which had been found perilous for cancer patients. It will be highly valuable when $99 \mathrm{mTC}$ is not available because it will not only reduce the surgical cost, it will also provide appropriate and timely triage to the endometrial cancer patients in this country.

\section{Acknowledgments}

None.

\section{Funding}

None.

\section{Conflicts of interest}

None of the authors has reported any conflicts of interest.

\section{References}

1. Surynt E, Reinholz-Jaskolska M, Bidzinski M. Laparoscopic sentinel lymph node mapping after cervical injection of indocyanine green for endometrial cancer-preliminary report. Videosurgery and Other Miniinvasive Techniques. 2015;10(3):406.

2. Papadia A, Imboden S, Siegenthaler F, et al. Laparoscopic indocyanine green sentinel lymph node mapping in endometrial cancer. Annals of surgical oncology. 2016;23(7):2206-2211.

3. Hagen B, Valla M, Aune G, et al. Indocyanine green fluorescence imaging of lymph nodes during robotic-assisted laparoscopic operation for endometrial cancer. A prospective validation study using a sentinel lymph node surgical algorithm. Gynecologic oncology. 2016;143(3):479-483.

4. Plante M, Touhami O, Trinh XB, et al. Sentinel node mapping with indocyanine green and endoscopic near-infrared fluorescence imaging in endometrial cancer. A pilot study and review of the literature. Gynecologic oncology. 2015;137(3):443-447.

5. Ruscito I, Gasparri ML, Braicu EI, et al. Sentinel node mapping in cervical and endometrial cancer: indocyanine green versus other conventional dyes - a meta-analysis. Annals of surgical oncology. 2016;23(11):37493756 .

6. Verbeek FP, Troyan SL, Mieog JSD, et al. Near-infrared fluorescence sentinel lymph node mapping in breast cancer: a multicenter experience. Breast cancer research and treatment. 2014;143(2):333-342.

7. Schaafsma BE, Verbeek FPR, Elzevier HW, et al. Optimization of sentinel lymph node mapping in bladder cancer using near-infrared fluorescence imaging. Journal of surgical oncology. 2014;110(7):845-850. 
8. Siesto G, Romano F, Fiamengo B, et al. Sentinel node mapping using indocyanine green and near-infrared fluorescence imaging technology for uterine malignancies: preliminary experience with the Da Vinci X system. Journal of minimally invasive gynecology. 2016;23(4):470-471.

9. Buda A, Crivellaro C, Elisei F, et al. Impact of Indocyanine Green for Sentinel Lymph Node Mapping in Early Stage Endometrial and Cervical Cancer: Comparison with Conventional Radiotracer 99m. Annals of surgical oncology. 2016;23(7):2183-2191.

10. Holloway RW, Ahmad S, Kendrick JE, et al. A prospective cohort study comparing colorimetric and fluorescent imaging for sentinel lymph node mapping in endometrial cancer. Annals of Surgical Oncology. 2017:1-8.

11. How J, Gotlieb WH, Press JZ, et al. Comparing indocyanine green, technetium, and blue dye for sentinel lymph node mapping in endometrial cancer. Gynecologic oncology. 2015;137(3):436-442.

12. Plante $\mathrm{M}$, Touhami $\mathrm{O}$, Trinh XB, et al. Is indocyanine green (ICG) the best tracer for sentinel lymph node (SLN) mapping in early-stage cervical and endometrial cancer?. Gynecologic Oncology. 2015;137:153.

13. Eriksson AG, Beavis A, Soslow RA, et al. A comparison of the detection of sentinel lymph nodes using indocyanine green and near-infrared fluorescence imaging versus blue dye during robotic surgery in uterine cancer. International Journal of Gynecological Cancer. 2017;27(4):743747 .

14. Jewell EL, Huang JJ, Abu-Rustum NR, et al. Detection of sentinel lymph nodes in minimally invasive surgery using indocyanine green and near-infrared fluorescence imaging for uterine and cervical malignancies. Gynecologic oncology. 2014;133(2):274-277.

15. Tran AM, Yang W, Boggess JF, et al. Bilateral SLN mapping for cervical cancer with ICG and robotic fluorescence imaging is associated with greater accuracy in detecting metastatic disease. Gynecologic Oncology. 2016;141:21

16. Choi HJ, Kim TJ, Lee YY, et al. Time-lapse imaging of sentinel lymph node using indocyanine green with near-infrared fluorescence imaging in early endometrial cancer. Journal of gynecologic oncology. 2016;27(3).
17. Laios A, Volpi D, Tullis ID, et al. A prospective pilot study of detection of sentinel lymph nodes in gynaecological cancers using a novel near infrared fluorescence imaging system. BMC research notes. 2015;8(1):608.

18. Vahrmeijer AL, Hutteman M, Van Der Vorst JR, et al. Image-guided cancer surgery using near-infrared fluorescence. Nature reviews Clinical oncology. 2013;10(9):507-518.

19. Rocha A, Domínguez AM, Lécuru F, et al. Indocyanine green and infrared fluorescence in detection of sentinel lymph nodes in endometrial and cervical cancer staging-a systematic review. European Journal of Obstetrics \& Gynecology and Reproductive Biology. 2016;206:213-219.

20. Imboden S, Papadia A, Nauwerk M, et al. A comparison of radiocolloid and indocyanine green fluorescence imaging, sentinel lymph node mapping in patients with cervical cancer undergoing laparoscopic surgery. Annals of surgical oncology. 2015;22(13):4198-4203.

21. Eriksson AGZ, Montovano M, Beavis A, et al. Impact of obesity on sentinel lymph node mapping in patients with newly diagnosed uterine cancer undergoing robotic surgery. Annals of surgical oncology. 2016;23(8):2522-2528.

22. Sinno AK, Fader AN, Roche KL, et al. A comparison of colorimetric versus fluorometric sentinel lymph node mapping during robotic surgery for endometrial cancer. Gynecologic oncology. 2014;134(2):281-286.

23. Darin MC, Gómez-Hidalgo NR, Westin SN, et al. Role of indocyanine green in sentinel node mapping in gynecologic cancer: is fluorescence imaging the new standard?. Journal of minimally invasive gynecology. 2016;23(2):186-193.

24. Papadia A, Gasparri ML, Buda A, et al. Sentinel lymph node mapping in endometrial cancer: comparison of fluorescence dye with traditional radiocolloid and blue. Journal of Cancer Research and Clinical Oncology. 2017;143(10):2039-2048.

25. Backes FJ, O'Malley DM, Salani R, et al. Adherence to a standard algorithm results in high negative predictive value of sentinel lymph node assessment using indocyanine green (ICG) and isosulfan blue (ISB) dyes in endometrial cancer. Gynecologic Oncology. 2015;137:39. 